\title{
Insights into Structure, Morphology and Reactivity of the Iron Oxide Based Fuel Borne Catalysts
}

\author{
P. Stelmachowski ${ }^{1}$ - A. Kopacz ${ }^{1} \cdot$ T. Jakubek ${ }^{1} \cdot$ P. Indyka ${ }^{1} \cdot$ J. Markowski $^{2}$ • \\ M. Wojtasik ${ }^{2}$ - L. Ziemiański ${ }^{2}$ W. Krasodomski ${ }^{2}$ G. Żak ${ }^{2}$ Z Z. Sojka ${ }^{1}$. \\ A. Kotarba ${ }^{1}$
}

Published online: 17 May 2016

(c) The Author(s) 2016. This article is published with open access at Springerlink.com

\begin{abstract}
Iron-based FBC additives with a different length of the organic stabilizing ligands: undecylenic acid (C11) and oleic acid (C18) were synthesized. A physicochemical characterization of the materials structure and morphology was performed by means of Raman spectroscopy, electron diffraction and TEM imaging. It was found that the reactivity of iron-based fuel borne catalysts depends on the length of the organic disperser and the size of the formed hematite nanoparticles. Reactivity tests performed in soot oxidation reaction both at a laboratory scale and in a commercial light oil burner revealed that the $\mathrm{C} 11$ stabilizer is more efficient than the $\mathrm{C} 18$ one in decreasing the emission of $\mathrm{CO}$ and soot particles.
\end{abstract}

Keywords FBC - Soot combustion - Iron - Catalyst . Hematite

\section{Introduction}

The emission of soot as a part of particulate matter (PM) pollutants from combustion of diesel and heating oils has become an issue of increased concern in the recent years. Breathing air polluted with soot can lead to serious lung, cardiovascular and heart diseases, as well as mutagenic changes. The overall adverse effect on health depends on its size and chemical composition [1]. From the

A. Kotarba

kotarba@chemia.uj.edu.pl

1 Faculty of Chemistry, Jagiellonian University in Kraków, ul. Ingardena 3, 30-060 Kraków, Poland

2 Oil and Gas Institute, National Research Institute, ul. Lubicz 25A, 31-503 Kraków, Poland environmental point of view, soot emission is considered as an important factor influencing global warming [2]. For these reasons solutions, such as diesel particulate filter for mobile sources, are being developed for soot emission abatement. The catalytic soot combustion appears to be the most promising abatement technology due to its efficiency and economic appeal [3]. Many catalytic materials (mainly oxides) have been investigated to decrease the temperature window of soot oxidation, but as for now the satisfactory practical solution has not been reached [4].

Iron oxide based materials $\left(\mathrm{Fe}_{\mathrm{x}} \mathrm{O}_{\mathrm{y}}\right)$ as the soot combustion catalysts have received a great deal of attention owing to their low price, environmental friendliness, high reactivity and susceptibility for facile surface and/or structural modifications. The iron oxide based materials catalytically active in this reaction are in the form of hematite [5-7], potassium ferrites [8, 9] or supported particles on alumina [10]. Another approach to the PM emission abatement is an application of the so-called Fuel Borne Catalysts (FBC) as a low concentration additives to liquid fuels [11, 12]. These additives are most often based on iron oxo/hydroxo complexes stabilized by long-tail organic ligands. The inorganic, iron-based content is in situ transformed during the combustion process into iron nanooxide (essentially hematite) combustion catalyst of soot [13, 14]. Despite their high dilution in the fuel, the FBCs are very efficient due to the effective dynamic intermingling of the nascent nanoparticles of the catalyst and soot in a gas phase, which is beneficial for increasing the number their mutual contact points. The oxygen transfer from the catalyst to the soot particles is thus facilitated, enhancing the combustion process $[12,15]$.

We have recently investigated the role of crystallite size of iron oxide catalyst for soot combustion, with a conclusion that the most active nanohematite particles comprised 
of crystals below $20 \mathrm{~nm}$. Moreover, hematite nanoparticles formed in situ in the laboratory and real process conditions of light fuel oil combustion with addition of fuel borne catalyst (FBC) precursors, exhibit a beneficial size range of 5-15 nm [16]. In the general context of in situ formation of catalytically active phase (FBC) in the form of nanoparticles the chemical structure of the employed organic dispersant and its effect on the combustion process of soot (carbon particles mingled with long-chain hydrocarbons), as well as formation of the active $\gamma-\mathrm{Fe}_{2} \mathrm{O}_{3}$ polymorph of the catalyst is necessary to elucidate. It is well known that the length of the organic stabilizer chain plays and important role in stabilization of the FBC precursor suspension. So far, however, there is no report in the scientific literature on its effect on the catalytic properties of the in situ formed iron-oxide catalyst. Thus, the aim of this study was to investigate the structure, morphology and soot oxidation reactivity in a laboratory and real conditions. In the latter case, the tests were performed in a light oil burner. The iron oxide based fuel borne catalysts stabilized by different tail length organic ligands were used for all the catalytic tests.

\section{Materials and Methods}

The FBC precursors were obtained by precipitation of hydroxyoxides from a solution of hydrate iron salts (iron(III) sulfate hydrate, exsiccated, puriss p.a., SigmaAldrich, Iron(II) sulfate hexahydrate, puriss, Chempur) by the addition of ammonia. The separated iron compounds were stabilized in an organic solvent by means of a selected organic acid. The organic acids used were undecylenic (C11) and oleic (C18). The iron content in the investigated samples was $3.7 \mathrm{wt} \%$ (Fe-C11) and, $14.1 \mathrm{wt} \%$ (Fe-C18).

As a base fuel for all commercial burner tests, a heating oil produced by Haltermann, meeting requirements of the DIN 51603 standard (Table 1) was used. All tested fuel formulations, with and without FBC precursors, were treated by a proper amount of lubricants to protect boiler elements against possible damage. All the investigated samples were added to the base fuel at a concentration equivalent to the iron content of $20 \mathrm{mg}$ per $\mathrm{kg}$ of fuel. The additional organic stabilizer was added to each blend to preserve the stability of the suspension. Samples of the blended fuel were mixed by the mechanical stirrer for $30 \mathrm{~min}$ at room temperature.

Particulate matter/soot from the light oil burner was collected on the silica end-pipe filters purifying exhaust gasses, located in a gravimetric unit for at least $60 \mathrm{~min}$. The corresponding exhaust gasses volume was in the range of $1-1.3 \mathrm{~m}^{3}$. The filters with the collected particular matter were weighed, and the result was expressed as the average hourly mass emission per normal cubic meter.

Temperature-programmed oxidation of model soot (Printex U, particle size $25 \mathrm{~nm}$, specific surface area $100 \mathrm{~m}^{2} \mathrm{~g}^{-1}$, additional characteristics can be found in [17]) was performed with a Mettler Toledo TGA/DSC1 using thermogravimetric analyses (TGA) method. The experiments were conducted under the air atmosphere (compress air of ambient humidity with the flow of $40 \mathrm{ml} / \mathrm{min}+$ purge Ar $20 \mathrm{ml} / \mathrm{min}$ ) at a temperature ramp of $10^{\circ} \mathrm{C} / \mathrm{min}$ in the range from room temperature to $800{ }^{\circ} \mathrm{C}$. The reaction mixtures (catalyst-soot) were prepared by impregnating the soot with the FBC precursor, ensuring the same amount of iron oxide phase. The soot to catalyst weight ratio was set to $5: 1$, which is a typical experimental proportion used in both tight contact and loose contact modes, and which varies usually from 1:4 to $1: 8[16,18]$. The wet contact applied in this study is closer to the tight contact mode, yet it provides better reproducibility of the soot oxidation tests results. In each measurement, $\sim 7 \mathrm{mg}$ of the sample (soot and catalyst mixture) was put in an alumina crucible. As a reference, each catalyst without soot was also examined for the mass loss and heat transfer in the investigated reaction temperature range to ensure that the observed mass changes can be associated with the soot oxidation process exclusively.

Light oil reactivity tests were performed in a system consisting of a commercial burner and analyzers: Oil furnace model Triplex Paromat, power $80 \mathrm{~kW}$ (Viessmann); Exhaust gas analyzer GA-40T (Madur) equipped with electrochemical and infrared sensors; Automatic gravimetric particulate matter analyzer P-10ZA (ZAM Kety). The test set-up allows for the measurements of carbon monoxide, nitrogen oxides, sulfur oxides, unburned hydrocarbons and dust/soot. The measurement cycle lasted $120 \mathrm{~min}$, wherein it was assumed that the start-up of the boiler and stabilization of the operating temperature of the installation took $30 \mathrm{~min}$, whereas the burning tests were monitored for $90 \mathrm{~min}$. The measurements were obtained in the 15 min intervals, with the values averaged over three independent measurements. The obtained results are summarized in Table 2.

In order to characterize the investigated samples by Raman spectroscopy, the diluted FBC precursor emulsions were sprayed onto quartz plates using a spray-gun, forming a thin layer. Each sample was sprayed onto 3 plates, 2 of which were flashed calcined (one in $300{ }^{\circ} \mathrm{C}$, the other in $\left.800{ }^{\circ} \mathrm{C}\right)$. The third plate was dried at room temperature. The end-pipe filters from the real boiler tests were investigated as received. The Raman spectra were recorded in ambient conditions using a Renishaw InVia spectrometer equipped with a Leica DMLM confocal microscope and a CCD detector, with an excitation wavelength of $785 \mathrm{~nm}$. 
Table 1 Base fuel properties

\begin{tabular}{lll}
\hline Fuel properties & Unit & Results \\
\hline Heating value & $\mathrm{MJ} / \mathrm{kg}$ & 43.216 \\
Density at $15{ }^{\circ} \mathrm{C}$ & $\mathrm{kg} / \mathrm{m}^{3}$ & 825.5 \\
Viscosity at $40{ }^{\circ} \mathrm{C}$ & $\mathrm{mm}{ }^{2} / \mathrm{s}$ & 4.115 \\
Sulphur content & $\mathrm{mg} / \mathrm{kg}$ & 2.4 \\
Flash point & ${ }^{\circ} \mathrm{C}$ & 87.5 \\
Carbon residue with $10 \%$ distillation residue & $\mathrm{wt} . \%$ & 0.018 \\
Ash & $\mathrm{wt} \% \%$ & 0.002 \\
Water content & $\mathrm{mg} / \mathrm{kg}$ & 30 \\
Oxidation stability, total containing residual insoluble components & $\mathrm{g} / \mathrm{m}^{3}$ & 4.0 \\
Fractional distillation & & \\
up to temperature $250{ }^{\circ} \mathrm{C}$ distillate & $\mathrm{vol} . \%$ & 30.5 \\
up to temperature $350{ }^{\circ} \mathrm{C}$ distillate & $\mathrm{vol} \%$ & 97.4 \\
Lubricity, corrected wear scar diameter (WS 1,4) & $\mu \mathrm{m}$ & 589 \\
\hline
\end{tabular}

Table 2 Parameters of the tests in the commercial burner with and without FBC addition

\begin{tabular}{|c|c|c|c|c|c|c|c|c|c|}
\hline units & $\begin{array}{l}\lambda^{*} \\
-\end{array}$ & $\begin{array}{c}T_{\mathrm{a}}^{* * *} \\
{ }^{\circ} \mathrm{C}\end{array}$ & $T_{\mathrm{g}}^{* * *}$ & $\begin{array}{l}\text { Fuel consumption } \\
1 / \mathrm{h}\end{array}$ & $\begin{array}{l}\text { Ambient pressure } \\
\mathrm{hPa}\end{array}$ & $\begin{array}{l}\text { Energy produced } \\
\text { GJ }\end{array}$ & $\begin{array}{l}\mathrm{O}_{2} \\
\text { vol. \% }\end{array}$ & $\mathrm{CO}_{2}$ & $\mathrm{CH}_{4}$ \\
\hline base fuel & 1.45 & 27 & 181 & 8.27 & - & 0.27 & 6.30 & 10.30 & 0.26 \\
\hline $\mathrm{Fe}-\mathrm{C} 11$ & 1.45 & 27 & 182 & 8.74 & 1001 & 0.36 & 7.00 & 10.60 & 0.10 \\
\hline $\mathrm{Fe}-\mathrm{C} 18$ & 1.44 & 25 & 183 & 8.30 & 988 & 0.30 & 6.43 & 10.66 & 0.24 \\
\hline
\end{tabular}

$* \lambda$ lambda-air to fuel ratio, $* * T_{\mathrm{a}}$-ambient temperature, $* * * T_{\mathrm{g}}$ - temperature of exhaust gasses

The laser power at the sample position was $1.5 \mathrm{~mW}$ with a magnification of $100 \times$. The Raman scattered light was collected in the spectral range of $100-2000 \mathrm{~cm}^{-1}$. At least 4 scans, $10 \mathrm{~s}$ each, were accumulated to ensure a sufficient signal to noise ratio.

A high resolution transmission electron microscope (FEI Tecnai Osiris) with X-FEG Schottky field emitter operated at accelerating voltage of $200 \mathrm{kV}$ was used to evaluate the fuel borne catalyst particles. Samples for TEM characterization were prepared in two ways: organic suspensions of the samples were dropped into a lacey carbon-coated copper grid and then dried at room temperature. Additionally, the diluted FBC precursor suspension was sprayed over the lacey carbon-coated copper grid and flash calcined at $800{ }^{\circ} \mathrm{C}$. Selected area electron diffraction (SAED) patterns were acquired in order to perform phase analysis of the precursors. Quantitative assessment of the nanoparticle size was performed using automated analysis method (Digital Micrograph, Gatan) applied to the TEM images.

\section{Results and Discussion}

Thermal combustion of the FBC precursors expressed in the form of DTA curves is presented in Fig. 1 along with the model soot (PU) oxidation curve. Both combustion profiles for $\mathrm{C} 11$ and $\mathrm{C} 18$ precursors are characterized by an

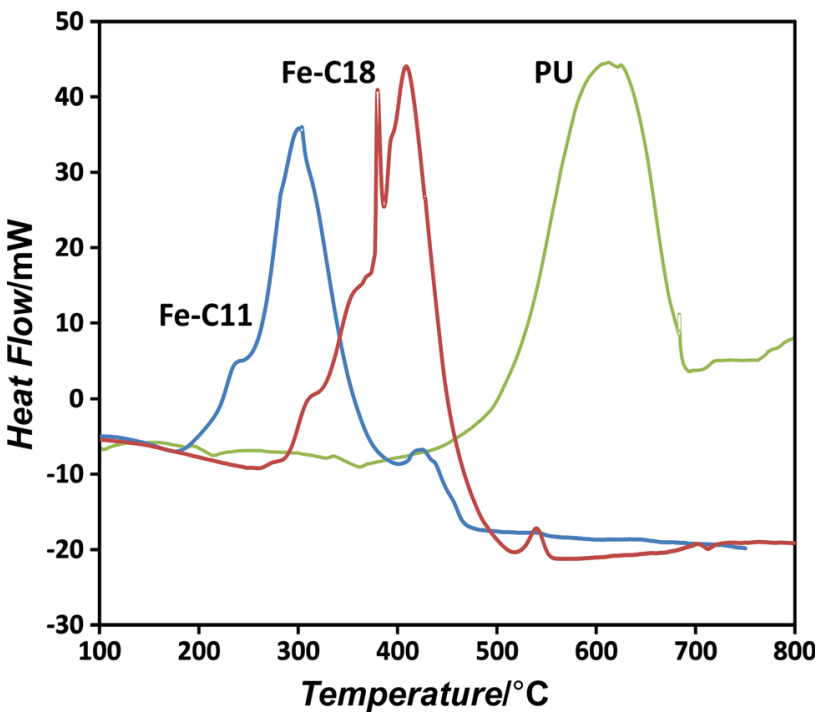

Fig. 1 DTA curves of the Fe-C11 and Fe-C18 precursors decomposition, and PU oxidation

intense exothermic peak resulting from the combustion of the stabilizing organic ligands. Decomposition in the air of the Fe-C11 precursor starts below $200{ }^{\circ} \mathrm{C}$, which is about $100{ }^{\circ} \mathrm{C}$ lower than the temperature of combustion of $\mathrm{Fe}$ C18. Similarly, the total combustion of the organic phase ends at a temperature of $100{ }^{\circ} \mathrm{C}$ lower for Fe-C11 than for Fe-C18 precursor. It can be concluded that in the absence 
of soot, the organic part of both additives is oxidized well below the temperature of model soot oxidation.

The results of the laboratory soot combustion catalytic tests are presented in Fig. 2. The soot conversion was calculated from the mass loss measured during the thermogravimetric analysis. Due to the strong exothermic effect of soot oxidation, the changes in heat transfer follow the mass loss of the catalyst-soot mixture, so the latter was used for the evaluation of the FBC catalyst activity. Comparison of the soot conversion curves with and without $\mathrm{Fe}-\mathrm{C} 18$ indicates that impregnation of model soot with the $\mathrm{Fe}-\mathrm{C} 18 \mathrm{FBC}$ precursor influences its oxidation temperature only at the beginning of the reaction. At higher temperature once the precursor is burned out the catalyzed and uncatalyzed soot conversion profiles merged. These results clearly show that the organic chain lowers the soot ignition onset. However, in the case of the Fe-C11 FBC precursor, the effect is more spectacular since not only the ignition temperature but also the whole soot combustion, are shifted to a much lower temperature. These findings can be interpreted in terms of the heat transfer from the organic chains oxidation (ignition stage) to soot combustion (burnout stage). Thus, the undecylenic acid based FBC catalyst lowers the temperature of the $50 \%$ conversion of soot by $\sim 200{ }^{\circ} \mathrm{C}$.

The results of the commercial burner tests of light oil combustion without and with FBC precursors addition are shown in Fig. 3. The emission levels of soot do not decrease upon addition of the Fe-C18 additive. The observed negligible emission increase can be accounted for

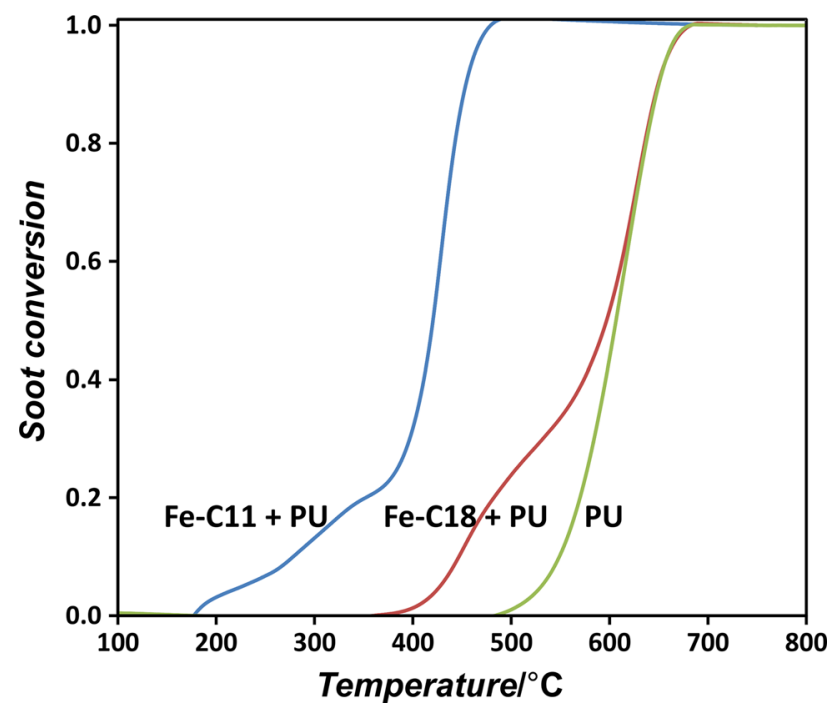

Fig. 2 Soot combustion tests with the Fe-C11 and Fe-C18 catalysts along with the model PU soot
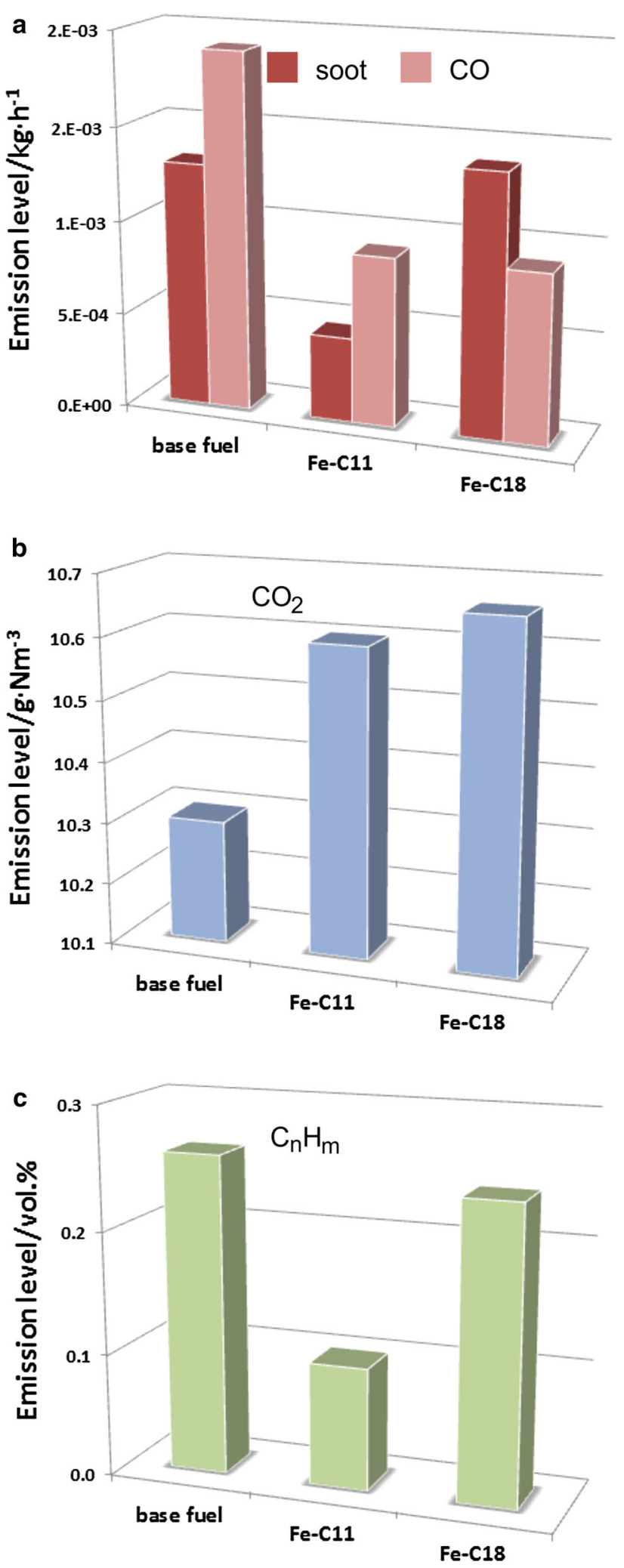

Fig. 3 Burner test results. Pollutants emission levels: a dark red soot, light red $\mathrm{CO}, \mathbf{b}$ blue carbon dioxide, $\mathbf{c}$ green hydrocarbons (as $\mathrm{CH}_{4}$ ) 
by the poorer reproducibility of the experiments carried out in a commercial burner in comparison to laboratory conditions. On the other hand, the application of the $\mathrm{Fe}-\mathrm{C} 11$ FBC precursor decreases the soot emission substantially. Carbon monoxide concentration in the exhaust gasses decreases significantly for fuel combustion for both Fe-C11 and Fe-C18 additives, as well. The observed better performance of the $\mathrm{Fe}-\mathrm{C} 11$ additive is exemplified by the concentration of the residual hydrocarbons, which is the lowest observed during the tests. The observed beneficial effect of the C11 precursor is thus in-line with the laboratory combustion results.

Due to a very high dispersion of the inorganic catalytic phase in the FBC precursor emulsion, the structural characterization could be performed by means of Raman spectroscopy. Raman spectra of the investigated samples are shown in Fig. 4. The narrow peaks at 225, 250, 299, $412,499,613$ and $1330 \mathrm{~cm}^{-1}$ originate from the hematite

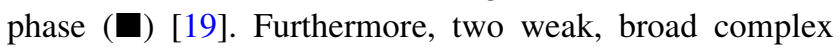
peaks at around 1350 and $1580 \mathrm{~cm}^{-1}$ for $\mathrm{Fe}-\mathrm{C} 11$ and $\mathrm{Fe}-$ C18 samples originate from vibrations of the remains of the organic solvent or stabilizer. The spectra of the two samples measured after drying at room temperature and calcination at $300{ }^{\circ} \mathrm{C}$ showed no well-defined peaks. The visible broad bands could be related to a maghemite phase [19]. All the samples showed only hematite phase on the plates flash-calcined at $800{ }^{\circ} \mathrm{C}$.

In Fig. 4 the Raman spectra collected from the end-pipe filters during burner test without and with the $\mathrm{Fe}-\mathrm{C} 18$ addition are presented. The particle matter collected while no catalyst was present displays bands typical for soot particles, with two wide complex peaks at around 1350 and $1580 \mathrm{~cm}^{-1}$ (spectrum a and b). These bands characteristic for soot were found all over the filter. The spectra of the PM collected on the second filter, where FBC was added to the fuel (spectrum $d$ and e), exhibit bands typical for iron oxide phases: hematite $(\boldsymbol{\square})$ and maghemite $(\boldsymbol{\Delta}-192,365$, 382,514 and $646 \mathrm{~cm}^{-1}$ [19]). Furthermore, very weak bands attributable to the soot particles are visible only after careful examination of the filter (spectrum c).

Figure 5 presents TEM images of FBC nanocrystals with $\mathrm{Fe}-\mathrm{C} 11$ and $\mathrm{Fe}-\mathrm{C} 18$ showing fairly regular rounded, equant shape, while flash calcined $\mathrm{Fe}-\mathrm{C} 18$ precursor leads to approximately polyhedral-shaped crystallites. By tracing maximum radius of the circular particles the average particle size from area-equivalent circle diameters was calculated. The particle size histograms in Fig. 5 show the $\mathrm{Fe}-$ $\mathrm{C} 11$ and $\mathrm{Fe}-\mathrm{C} 18$ monodisperse distribution with a mean particle size well approximated with a Gaussian distribution of about 5.6 and $7.0 \mathrm{~nm}$, respectively. While in
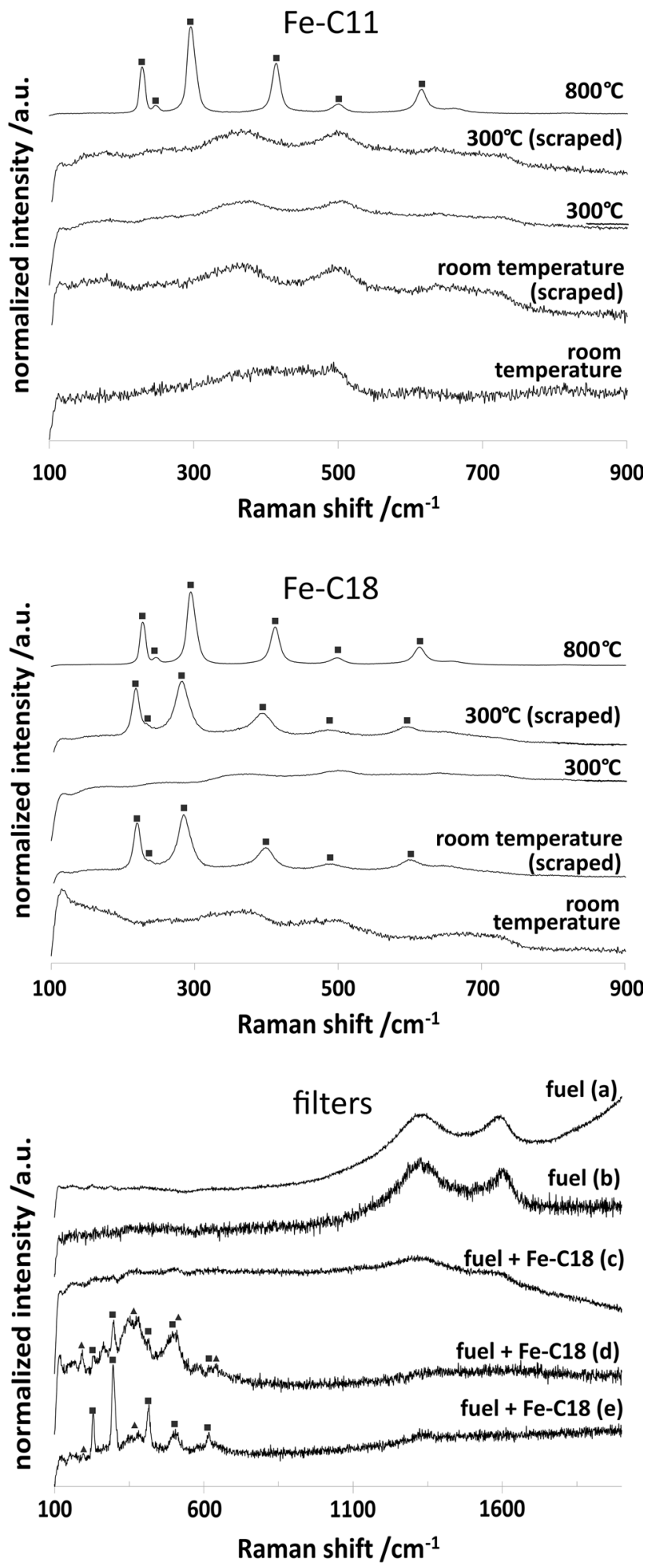

Fig. 4 Raman spectra of dried and flash calcined Fe-C11, Fe-C18 FBC precursors and filters from light oil combustion tests with collected PM from fuel without $\operatorname{FBC}$ precursor $(a, b)$ and with $\mathrm{Fe}-\mathrm{C} 18$ $(d, e, f)$. Filled square hematite, filled triangle maghemite 

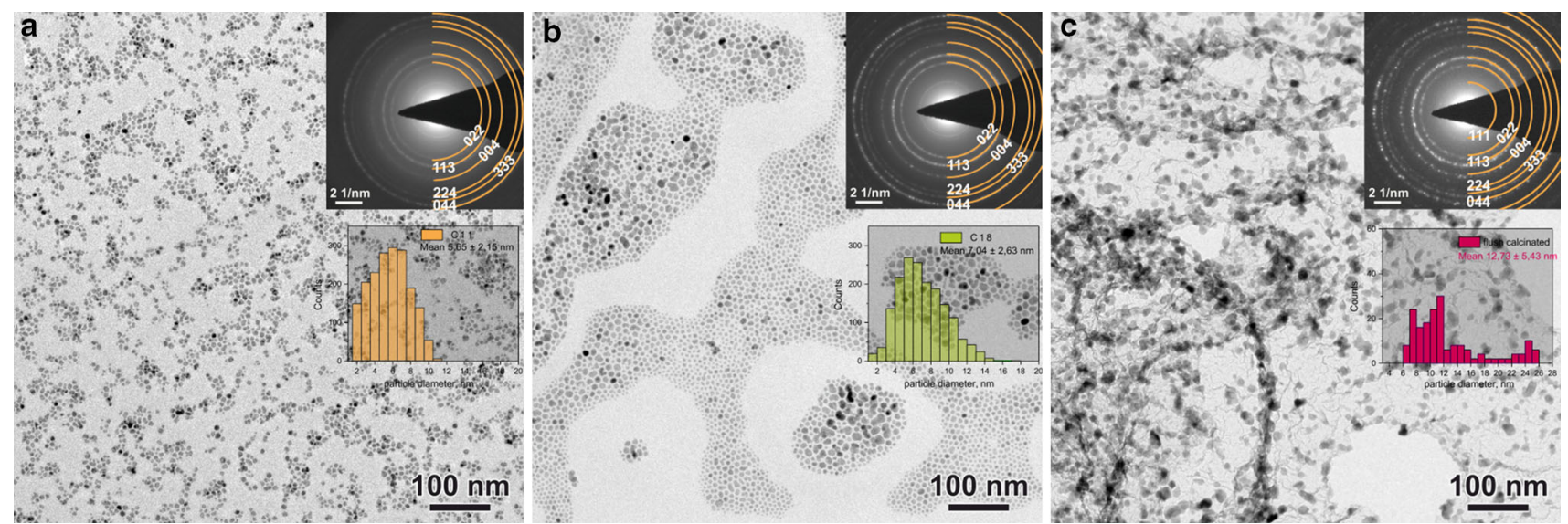

Fig. 5 TEM images of the a Fe-C11, b Fe-C18 and $\mathbf{c}$ flash calcined $\mathrm{Fe}-\mathrm{C} 18$ precursors along with the electron diffraction phase analysis (confirming magnetite phase) and particle size distribution histograms

comparison to $\mathrm{Fe}-\mathrm{C} 11$ precursor the $\mathrm{Fe}-\mathrm{C} 18$ showed broader distribution (with the tail towards the larger particle size), the flash calcined $\mathrm{Fe}-\mathrm{C} 18$ precursor gave rise to even more spread distribution of the particle sizes.

The corresponding electron diffraction patterns (SAED) of the FBC precursors (Fig. 5) show fairly complete rings of diffraction spots, complemented with the Miller indexes of the cubic $\mathrm{Fe}_{3} \mathrm{O}_{4}$ magnetite phase (AMSCD 0000945) and the $\gamma-\mathrm{Fe}_{2} \mathrm{O}_{3}$ maghemite phase (AMSCD 0007898). HRTEM alone is not sufficient to fully distinguish between the two spinel structures of the $\mathrm{Fe}_{3} \mathrm{O}_{4}$ and $\gamma-\mathrm{Fe}_{2} \mathrm{O}_{3}$ oxides. This distinction on a macroscale can be made by means of the Raman spectroscopy, where spectrum characteristic for iron(III) oxide as maghemite was observed. The electron diffraction data obtained from flash calcined $\mathrm{Fe}-\mathrm{C} 18$ of larger particle sizes becomes more sparse and spot-like, in comparison to the $\mathrm{Fe}-\mathrm{C} 11$ and $\mathrm{Fe}-\mathrm{C} 18$ samples dried at room temperature.

The use of oleic acid (C18) or its derivatives such as olein, a cheaply available at a technical scale stabilizing agent, results in improved combustion in the burner tests, despite the negligible activity of $\mathrm{Fe}-\mathrm{C} 18$ in a direct soot combustion tests. Shorter organic ligands, C11, due to their lower thermal stability shift the ignition temperature and the soot burning to lower values improving the whole combustion efficiency. Moreover, the average size of the FBC particles produced from the $\mathrm{Fe}-\mathrm{C} 11$ precursor is lower than for $\mathrm{Fe}-\mathrm{C} 18$, which is also beneficial for the soot combustion as shown by us recently [16].

\section{Conclusions}

Two FBC additives were synthesized and tested in the soot oxidation reaction both at a laboratory scale and in the commercial light oil burner. The main difference between the samples was the length of the organic stabilizing ligand: undecylenic acid (C11) and oleic acid (C18). It was found that the reactivity of iron-based fuel borne catalysts depends strongly on the length of the organic disperser and the crystallite size of the formed iron-oxide nanoparticles. The results of the laboratory test using the model soot were confirmed by the commercial burner tests. As a result, a three-fold beneficial effect of the organic ligands was proposed, which consists in the stabilization of the FBC precursor suspension, control of the in situ formed ironoxide nanocatalyst particle size, and lowering of the lightoff temperature of soot oxidation. The latter effect is particularly well pronounced in the case of the Fe-C11 FBC precursor with undecylenic acid as a stabilizing agent.

Acknowledgments Authors would like to acknowledge the Polish National Centre for Research and Development funding awarded by the decision number PBS1/B1/4/2012.The research was carried out with the equipment purchased thanks to the financial support of the European Regional Development Fund in the framework of the Polish Innovation Economy Operational Program (contract no. POIG.02.01.00-12-023/08).

Open Access This article is distributed under the terms of the Creative Commons Attribution 4.0 International License (http://crea tivecommons.org/licenses/by/4.0/), which permits unrestricted use, distribution, and reproduction in any medium, provided you give appropriate credit to the original author(s) and the source, provide a link to the Creative Commons license, and indicate if changes were made.

\section{References}

1. Nichols JL, Oesterling Owens E, Dutton SJ, Luben TJ (2013) Int J Public Health 58:707

2. Jacobson MZ (2010) J Geophys Res D 115:24

3. Fino D (2007) Sci Technol Adv Mater 8:93

4. Bueno-López A (2014) Appl Catal B: Environ 146:1

5. Wagloehner S, Kureti S (2012) Appl Catal B: Environ 125:158 
6. Wagloehner S, Kureti S (2013) Appl Catal B: Environ 129:501

7. Wagloehner S, Baer JN, Kureti S (2014) Appl Catal B: Environ 147:1000

8. Legutko P, Stelmachowski P, Trębala M, Sojka Z, Kotarba A (2013) Top Catal 56:489

9. Legutko P, Kaspera W, Jakubek T, Stelmachowski P, Kotarba A (2013) Top Catal 56:745-749

10. Gálvez ME, Ascaso S, Stelmachowski P, Legutko P, Kotarba A, Moliner R, Lázaro MJ (2014) Appl Catal B: Environ 152-153:88

11. Kannan GR, Karvembu R, Anand R (2011) Appl Energy 88: 3694

12. Song J, Wang J, Boehman AL (2006) Combust Flame 146:73

13. Nash DG, Swanson NB, Preston WT, Yelverton TLB, Roberts WL, Wendt JOL, Linak WP (2013) J Aerosol Sci 58:50
14. Heeb NV, Schmid P, Kohler M, Gujer E, Zennegg M, Wenger D, Wichser A, Ulrich A, Gfeller U, Honegger P, Zeyer K, Emmenegger L, Petermann JL, Czerwinski J, Mosimann T, Kasper M, Mayer A (2008) Environ Sci Technol 42:3773

15. Zasada F, Piskorz W, Stelmachowski P, Legutko P, Kotarba A, Sojka Z (2015) J Phys Chem C 119:6568

16. Stelmachowski P, Kopacz A, Legutko P, Indyka P, Wojtasik M, Ziemiański L, Zak G, Sojka Z, Kotarba A (2015) Catal Today 257:111-116

17. http://www.oecliterature.com/pdf/OEC-3130-carbonblackpolymer samerica.pdf. Accessed 24 June 2015

18. Hensgen L, Stöwe K (2011) Catal Today 159:100-107

19. de Faria DLA, Silva SV, de Oliveira MT (1997) J Raman Spectrosc 28:878 